\title{
Neurocognitive Characteristics of Individuals with Irritable Bowel Syndrome
}

\author{
KMF Wong, SSY Yuen, ADP Mak
}

\begin{abstract}
Irritable bowel syndrome (IBS) is a systems-based brain-gut axis disorder. Cognitive functions reflect central affective and attentional processes that are driven by genetic and epigenetic influences and effect complex brain-gut interactions. These interactions include stress-induced changes in hypothalamicpituitary-adrenal axis and autonomic nervous system, remodelling of the immune system, and alterations in microbiota composition. This review summarises current neurocognitive findings on patients with IBS. 13 studies of neurocognition in IBS patients were identified from PubMed, Ovid MEDLINE, EMBASE, and PsycINFO. The methodology and relevant findings were systematically analysed. There are alterations in both hot and cold cognitions in IBS patients. Consistently, attentional bias towards negative emotionally valenced and gastrointestinal symptom-related stimuli is found in hot cognition tasks, with other cold cognition differences including frontal executive dysfunction and stress-related hippocampal-mediated cognitive alterations. The effect of psychiatric comorbidity on a disorder level, as well as illness chronicity, on cognitive alterations requires further examination. Attentional bias and executive dysfunction in IBS gave support to its neural network alterations accounting for visceral hypersensitivity. Further prospective neuropsychological studies should examine the effect of chronicity, current symptom severity, and psychiatric comorbidity on the cognition in different IBS subtypes.
\end{abstract}

Key words: Cognition; Irritable bowel syndrome; Neuropsychological test

Kenneth Man-fung Wong, MBChB, Department of Psychiatry, Shatin Hospital, Hong Kong

Snowy Suet-ying Yuen, BSSC, MA, Department of Psychiatry, The Chinese University of Hong Kong, Hong Kong

Arthur Dun-ping Mak, MBChB, FRCPsych(UK), FHKCPsych, FHKAM(Psychiatry), Department of Psychiatry, The Chinese University of Hong Kong, Hong Kong

Address for correspondence: Dr Arthur Dun-ping Mak, Department of Psychiatry, The Chinese University of Hong Kong, Hong Kong. Email: arthurdpmak@cuhk.edu.hk

Submitted: 4 September 2018; Accepted: 12 February 2019

\section{Introduction}

Irritable bowel syndrome (IBS) is a common functional gastrointestinal disorder affecting 5\% to $15 \%$ of the population worldwide, ${ }^{1,2}$ with significant healthcare costs and impairment. ${ }^{3}$ It is characterised by chronic recurring abdominal pain and altered bowel habits in the absence of organic disease (Table 1), and is classified into four subtypes: IBS with predominant diarrhoea (IBS-D), IBS with predominant constipation (IBS-C), IBS with mixed bowel habits (IBS-mixed), and unclassified. In a random community-based telephone survey conducted in Hong Kong, the proportions for the corresponding subtypes were $38 \%, 20.4 \%, 6.4 \%$, and $35.2 \%$. $^{2}$

IBS is a multi-system disorder of the brain-gut axis with multiple biopsychosocial aetiologies. ${ }^{4}$ Digestive processes are influenced by interactions between hypothalamuspituitary-adrenal (HPA) axis, autonomic nervous system, and inflammatory and central pain modulation systems. ${ }^{5} \mathrm{~A}$ core feature of IBS is central visceral hypersensitivity, which is characterised by increased salience and selective attention to sensory input from the gut, descending pain facilitation, impairment of fear conditioning, and extinction learning. ${ }^{6}$ Interactions of complex systems involving heightened sympathetic output, vagal dysfunction, increased immune activation, increased gastrointestinal epithelial permeability, and reduced gut microbial biodiversity contribute to IBS symptoms and pathophysiology. Strong evidence suggests an association of IBS with genes that regulate HPA axis, serotonin-signalling system, and catecholaminergic signalling and inflammatory pathways. ${ }^{7-9}$ In addition, stressful life events, early-life adversities, dietary factors, and pathogenic microorganisms ${ }^{10,11}$ have been shown to alter gene expression and contribute to IBS.

Anxiety and depression are highly implicated in IBS, and cognitive dysfunctions may be found in patients with depression and anxiety. However, earlier work focused on selective processing bias in terms of the cognitive behavioural model of affective disorders. Newer neuroscientific research identified aberrations in neural circuitries, systemic stress response, immune activation, and gut microbiota composition in patients with IBS; all of which are purported to affect cognitive processes in IBS based on the cognitive neurobiological model. ${ }^{12}$

\section{Neural Circuits}

In a meta-analysis of neuroimaging studies that investigated activities of neural networks during rectal distension, ${ }^{13}$ 
Table 1. Rome IV criteria for diagnosing irritable bowel syndrome (IBS) and subtypes ${ }^{* 60}$

\begin{tabular}{|c|c|c|}
\hline \multirow[t]{2}{*}{ Subtypes } & \multicolumn{2}{|c|}{ Stool form \% on days with at least one abnormal bowel movement } \\
\hline & Bristol stool types 1, 2 (very hard stool) & Bristol stool types 3, 4 (very loose stool) \\
\hline IBS-C & $>25 \%$ & $<25 \%$ \\
\hline IBS-D & $<25 \%$ & $>25 \%$ \\
\hline IBS-M & $>25 \%$ & $>25 \%$ \\
\hline IBS-unclassified & $\begin{array}{l}\text { IBS criteria met but bowel habits canno } \\
\text { three subtypes }\end{array}$ & curately classified into one of the above \\
\hline
\end{tabular}

Recurrent abdominal pain, on average, at least 1 day/week in the last 3 months and associated with $\geq 2$ of the following criteria: (1) related to defecation, (2) associated with a change in frequency of stool, (3) associated with a change in form (appearance) of stool. Criteria fulfilled for the last 3 months with symptom onset at least 6 months before diagnosis

consistently there is hyperactivity of the salience (anterior insula and anterior mid-cingulate cortex), emotional arousal (pregenual anterior cingulate cortex, amygdala, hippocampus), and autonomic networks (subgenual anterior cingulate cortex, amygdala, pontine-medulla), while the central executive network (dorsolateral prefrontal cortex) is hypoactive. Failed engagement of the central executive network is related to impaired modulation of pain and emotion, whereas the hyperactive salience network exerts its effect via its connection with emotional arousal and autonomic networks, leading to visceral hypersensitivity and heightened stress response. These neural circuitry dysfunctions may underlie impaired cognitive function in IBS. Of note, hypoactivity of the dorsolateral prefrontal cortex is related to attentional bias, catastrophisation, and executive dysfunction,,$^{14}$ whereas hyperactivity of anterior cingulate cortex and limbic system may contribute to the impairment in emotion-related cognitive functions, such as facilitated Stroop effect in emotional Stroop test. ${ }^{15}$

\section{Stress Response, Immune System}

IBS is characterised by heightened stress response mediated by activation of HPA axis and autonomic nervous system, resulting in altered gut motility and bowel transit. Neurocognitively, high cortisol level may affect cognition, particularly impairment of hippocampal-mediated episodic memory, ${ }^{16,17}$ prefrontal-mediated extinction learning and working memory, ${ }^{18,19}$ and enhancement of amygdalamediated cued fear learning. ${ }^{20}$ In a positron emission tomography computed tomography study, the level of noradrenaline may affect attention and working memory through enhanced connectivity between parietal and frontal regions. ${ }^{21}$ In animal studies, modest level of noradrenaline in aroused state may improve working memory via alpha-2 receptors activation, ${ }^{22}$ but a stress-induced large increase in noradrenaline may activate alpha- 1 receptors and disengage prefrontal cortex, leading to impaired executive functions and working memory. ${ }^{23,24}$

\section{Microbiome}

Interactions between microbiome and the enteric nervous system, mucosal and systemic immune system is a key factor in the pathogenesis of IBS. There is different composition of microbiota between IBS patients and healthy subjects. ${ }^{25}$ Modulation of microbiota, by probiotics for instance, improves IBS symptoms. ${ }^{26}$ Microbiome is relevant to symptom production; altered microbiota composition gives rise to cognitive dysfunction in rodents, such as impaired hippocampal-mediated memory and object recognition. ${ }^{27}$ In humans, actinobacteria phylum abundance is associated with speed, attention, and cognitive flexibility measured by the Trail Making Test. ${ }^{28}$ However, no studies have investigated the correlation between cognitive dysfunction and difference in microbiota composition specifically in IBS patients.

\section{Chronic pain}

Chronic recurrent abdominal pain is one of the cardinal features of IBS. The relationship between pain and cognitive dysfunctions has been widely studied in the somatic pain field. On the one hand, cognitive processes modulate pain perception in a 'top-down' manner via distraction and cognitive reappraisal. ${ }^{29}$ On the other hand, pain disrupts cognitive processes. ${ }^{30}$ For example, patients with chronic pain conditions were found to have impaired attention, working memory, episodic memory, and executive functioning. ${ }^{31}$ Cognitive alteration may occur in patients with IBS by pain-mediated mechanisms.

There are various extents and types of cognitive dysfunction in patients with IBS. We conducted a comprehensive review of the literature to summarise the existing evidence and to determine future research directions.

\section{Methods}

The PubMed, Ovid MEDLINE, EMBASE, and PsycINFO databases were searched using keywords: 'irritable bowel syndrome', 'IBS', 'cognitive', 'neurocognitive', 'neuropsychological tests', 'executive function', 'attention', 'attention bias', 'memory', 'perception', 'language', 'intelligence'. Studies that evaluated cognitive function of patients with IBS measured by the Rome or Manning criteria were included. References of the retrieved articles were reviewed to look for relevant studies. Studies not 
written in English were excluded, as were animal studies.

\section{Discussion}

A total of 13 studies were identified and classified into 'hot' and 'cold' cognitions (Table 2). The nature of cognitive dysfunctions, differences across IBS subtypes, and the impact of comorbid anxiety/depression were elaborated. Hot cognitions refer to cognitive attributes influenced by affective states. They are fast, reflexive and relatively simple ${ }^{32}$ elicited using emotionally valenced stimuli. Hot cognitions were examined using gastrointestinal symptomrelated tasks in addition to emotionally valenced stimuli.Cold cognitions refer to cognitive attributes that are independent of emotional involvement. They are characterised by self-control and are comparatively slow, reflective, and complex. ${ }^{32}$ Cold cognitions encompass executive function, working memory, attention, and episodic memory, and may reflect pathophysiological impact underpinning to the neurobiology of IBS. These processes include chronic pain, stress response, and immune activation; all are elements of IBS that have salient cognitive implications and are conceptualised in the cognitive neurobiological model. ${ }^{12}$

\section{Hot cognitions \\ Memory Tasks}

Three early neurocognitive studies on IBS patients used word recognition/recall tests to assess selective recall. ${ }^{33-35}$ Subjects were asked to identify words in different categories, such as neutral, negative, positive, and gastrointestinal symptom-related words, followed by a recall task. Consistently, IBS patients had a selective bias in recalling or reacting to emotionally negative information. Selective recognition and recall increased in patients with IBS compared with patients with organic gastrointestinal disease and asthma, with false positive errors in recognition of gastrointestinal-related words ${ }^{35}$ and emotionally negative words ${ }^{33}$ that appeared unique to IBS patients. IBS patients showed faster recognition to all kinds of stimuli, compared with patients with organic gastrointestinal disorders, suggesting hypervigilance. ${ }^{35}$ In addition, IBS patients (with and without depressive symptoms) showed similarly increased bias to emotionally negative words as in depressed patients. ${ }^{33}$ These findings suggest a bias towards recalling negatively valenced information and hypervigilance in IBS patients that is similar to depression and distinct from patients with organic diseases, yet not explained wholly by concomitant depressive symptoms.

\section{Modified Stroop tests}

Modified Strooptests that include emotionally valenced words and gastrointestinal symptom-related words as a distraction to the word colours were used to prove selective information processing in IBS patients. ${ }^{36,37}$ There was significant Stroop interference in IBS patients from gastrointestinal symptomrelated words, suggesting selective processing of these words. The effect was only significant in subliminally presented words, suggesting that the cognitive process involved was outside the realm of conscious processing. Only in IBS patients, trait anxiety and visceral anxiety were associated with Stroop facilitation elicited by situational threat words, suggesting threat-evaluation driven attentional bias in IBS patients with anxiety. ${ }^{37}$

\section{Exogenous Cueing Task}

The exogenous cueing task is used to assess the engagement/ disengagement components of attention in social threat and pain-related information. ${ }^{38}$ Subjects were asked to tell the location (left or right) of a dot probe after they were shown words of various categories on either side. Relative to controls, IBS patients showed increased bias towards pain words but not social threat words, compared to neutral words with faster engagement. The pain bias correlated with somatic symptoms and illness behaviour, independent of Hospital Anxiety and Depression Scale scores. This suggests clinical significance of attentional bias in explaining somatic symptoms and illness behaviour, and supports its role in a vicious circle maintenance model of IBS, in which attentional bias exacerbates symptom perception and illness behaviour, and increases salience allocated to pain.

In a study of patients with putative functional gastrointestinal disorders (rather than IBS), ${ }^{39}$ the word task was presented for a shorter period to avoid the effect of conscious processing and to allow assessment of automatic orienting, with an induction block of either rumination or distraction added. After the rumination block, IBS patients oriented more to social threat words than controls but responded similarly to neutral and pain words ${ }^{39}$ The results were independent of anxiety and depression symptom ratings. These findings suggest that the effect of rumination on reinforcing pre-conscious attentional bias to negatively valenced information did not have the same specificity to pain in the task capturing effects of conscious process.

\section{Cold cognitions \\ Memory Tasks}

In a study comparing patients with IBS or Crohn's disease and healthy subjects on visuospatial episodic memory using Paired Associate Learning from the Cambridge Neuropsychological Test Automated Battery, ${ }^{40}$ IBS patients showed impaired performance that was associated with lower basal morning cortisol levels, independent of anxiety and depression symptom ratings. This suggests hippocampalmediated visuospatial memory impairment in IBS that was stress-related but not explained by anxiety and depressive symptoms. However, in another study using Paired Associates Learning to compare patients with IBS or inflammatory bowel disease and healthy controls, no difference was reported across groups. ${ }^{41}$ A further study reported no difference between patients with IBS or inflammatory bowel disease and controls in terms of spatial and object recognition memory assessed by a computer-generated virtual environment, in which subjects were asked to identify target objects and underwent spatial recognition test. ${ }^{42}$ 


\section{Attention Task: Attention Network Test}

In a study using the Attention Network Test and functional resonance imaging to evaluate the core attentional network, ${ }^{43}$ IBS patients were found to have shorter reaction time during alerting and orienting conditions, which were associated with greater activation of anterior mid-cingulate cortex and insula, and decreased activity in the right inferior frontal junction and supplementary motor cortex. Activity of anterior mid-cingulate cortex during alerting was positively correlated with gastrointestinal symptoms duration and overall severity. These findings suggest that in IBS patients, altered attention network engagement may underlie symptom-related anxiety, hypervigilance, and visceral hypersensitivity.

\section{Frontal Executive Function}

Working memory was tested using the forward digit span task and Spatial Working Memory task of the Cambridge Neuropsychological Test Automated Battery; no difference was reported between patients with IBS and healthy controls. ${ }^{40,41}$ The traditional Stroop test was used to evaluate cognitive flexibility and response inhibition, and reported no significant impairment in IBS patients. ${ }^{40-42}$ Similarly there was no significant impairment in patients with IBS or Crohn's disease (compared with healthy controls) in terms of the Intra-Extra Dimensional Set Shift, but it is uncertain whether most of the IBS patients were of mixed IBS subtype. ${ }^{40}$ However, IBS patients were found to have increased perseverative errors and set maintenance difficulty (based on the Wisconsin Card Sorting Test) that was associated with reduced dorsolateral prefrontal cortex / pre-supplementary motor area connectivity, implicating impairment in cognitive flexibility. ${ }^{44}$ The study sample consisted of equal numbers of diarrhoea and constipation predominant types and may explain the discrepancies in executive function, given the heterogeneity in frontal attentional circuits and related physiological parameters in different IBS subtypes.

\section{Verbal IQ and Performance IQ Discrepancy}

In a study evaluating the effect of chronic illness on verbal and nonverbal cognitive functioning using the Weschler Abbreviated Scale of Intelligence, ${ }^{42}$ patients with IBS had lower verbal IQ relative to own performance IQ than healthy controls, even after controlling for depressive symptoms and chronicity. Similar verbal/performance IQ discrepancy was reported in patients with early-onset diabetes ${ }^{45}$ and autism, ${ }^{46}$ but the implications in IBS remained uncertain.

\section{Verbal Versus Spatial Cognitive Tests}

In a study using two paper-and-pencil tests to evaluate verbal versus spatial performances as a measure of cognitive style and approximation of hemispheric preference, ${ }^{47}$ in the analysis of thresholds of minimal colonic distension sensitivity, in IBS patients the spatial participants had lower thresholds than the verbal participants, and the reverse was true in healthy controls. These findings suggest covert changes in the brain related to abnormal sensory functions of the gut.

\section{Hot and Cold Cognitive Impairment in IBS}

The evidence suggests that IBS patients have impairment in hot cognitions including both attentional bias to negative emotionally valenced and gastrointestinal symptom-related information, as well as hypervigilance for pain. Compatible with learning theory models ${ }^{48}$ that explain how illness experience can be conditioned with autonomic arousals on subsequent exposures to exacerbate anxiety sensitivity in anxiety disorders, emotional and visceral attentional biases in IBS patients can be understood as the consequence of 'salience computation', as IBS patients developed heightened awareness and sensitivity after recurrent exposure to gastrointestinal symptoms and the associated actual or perceived threats. ${ }^{6}$

Cold cognitions, especially the frontal executive dysfunction, play a role in the 'top-down' cognitive control of arousal responses in a complex interaction with other brain regions. Imaging evidence shows hypoactivity of dorsolateral prefrontal cortex in IBS patients. ${ }^{13}$ The abnormality is related to impaired inhibitory control over pain, emotion, and attention that are mediated by a complex cognitiveaffective network. The related cognitive dysfunctions, such as impairment of set-shifting and inhibition, in IBS patients are believed to fail in suppressing attention to irrelevant and distracting stimuli, leading to compromised working memory and attention, catastrophisation, heightened anxiety level and stress response. ${ }^{49}$

\section{Correlations of Cognition with Bowel Symptoms and Chronicity}

Examining correlations of cognitive function with bowel symptoms and chronicity may give insights into the extent of cognitive impairment, current illness activity, and effect of chronic morbidity. Regarding hot cognitions, no correlation was found between selective recognition/recall and bowel symptom measures in IBS patients. ${ }^{35}$ However, attentional bias was found to be associated with somatic symptom severity and behaviour in IBS patients. ${ }^{39}$ However, these studies did not measure bowel symptom chronicity. Only one study of patients with putative functional gastrointestinal disorders reported that the time since IBS diagnosis positively correlated with attentional bias to social threats. ${ }^{39}$

For cold cognitions, a positive correlation was found between executive dysfunction with bowel symptom severity. ${ }^{43}$ Only one study measured both correlations of cognition with bowel symptom severity and chronicity and reported no such correlations in terms of hippocampal memory tests. ${ }^{40}$ The lack of correlation between pain severity and hippocampal-mediated memory in contrast to significant correlation between pain and prefrontal measures of alerting and executive control efficiency suggests a more prominent role of altered prefrontal cognitive processes in accounting for impaired pain inhibition. However, heterogeneity in sample composition and cognitive measures used in these two studies may render this conclusion premature. 
Table 2. Studies of cognitive functions in patients with irritable bowel syndrome (IBS)

\begin{tabular}{|c|c|c|c|c|}
\hline Study & Subject characteristic & Tests applied & Cognitive domains tested & Anxiety/depression assessment \\
\hline $\begin{array}{l}\text { Gomborone } \\
\text { et al, },^{33} 1993\end{array}$ & $\begin{array}{l}30 \text { IBS vs } 28 \text { depressed vs } 28 \\
\text { organic gastrointestinal vs } 30 \\
\text { healthy controls; median age: } 36 \\
\text { vs } 38 \text { vs } 27 \text { vs } 35 ; \mathrm{M}: \mathrm{F}=1: 2\end{array}$ & Word recognition memory test & $\begin{array}{l}\text { Hot cognition: episodic/ } \\
\text { declarative memory }\end{array}$ & $\begin{array}{l}\text { Hospital Anxiety and Depression } \\
\text { Scale, Beck Depression } \\
\text { Inventory }\end{array}$ \\
\hline 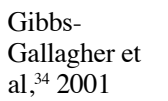 & $\begin{array}{l}16 \text { IBS vs } 9 \text { asthma vs } 8 \text { healthy } \\
\text { controls; mean age: } 44 \text { vs } 39 \text { vs } \\
34 \text {; all IBS subjects were females }\end{array}$ & Word recall task & $\begin{array}{l}\text { Hot cognition: selective } \\
\text { attention, episodic/declarative } \\
\text { memory }\end{array}$ & - \\
\hline $\begin{array}{l}\text { Afzal et al, }{ }^{36} \\
2006\end{array}$ & $\begin{array}{l}15 \text { IBS and } 15 \text { age- and sex- } \\
\text { matched controls; mean age: } 30\end{array}$ & $\begin{array}{l}\text { Modified Stroop Task: } \\
\text { gastrointestinal symptom-related } \\
\text { words, presented subliminally and } \\
\text { supraliminally }\end{array}$ & $\begin{array}{l}\text { Hot cognition: selective } \\
\text { attention, cognitive flexibility } \\
\text { and inhibition }\end{array}$ & - \\
\hline $\begin{array}{l}\text { Posserud et } \\
\mathrm{al},{ }^{35} 2009\end{array}$ & $\begin{array}{l}36 \text { IBS vs } 40 \text { organic } \\
\text { gastrointestinal (inflammatory } \\
\text { bowel disease and celiac } \\
\text { disease); mean age: } 35 ; \mathrm{M}: \mathrm{F}= \\
\text { 3:5 }\end{array}$ & $\begin{array}{l}\text { Word association/recognition/ } \\
\text { recollection }\end{array}$ & $\begin{array}{l}\text { Hot cognition: episodic/ } \\
\text { declarative memory }\end{array}$ & $\begin{array}{l}\text { Hospital Anxiety and Depression } \\
\text { Scale }\end{array}$ \\
\hline $\begin{array}{l}\text { Martin and } \\
\text { Chapman }{ }^{39} \\
2010\end{array}$ & $\begin{array}{l}33 \text { putative functional } \\
\text { gastrointestinal disorders vs } 27 \\
\text { healthy controls; mean age: } 44 \text { vs } \\
46 \text {; all females; no formal dx of } \\
\text { IBS made }\end{array}$ & $\begin{array}{l}\text { Modified exogenous cueing tasks } \\
\text { with rumination or distraction } \\
\text { induction in between }\end{array}$ & $\begin{array}{l}\text { Hot cognition: selective } \\
\text { attention }\end{array}$ & $\begin{array}{l}\text { Hospital Anxiety and Depression } \\
\text { Scale }\end{array}$ \\
\hline $\begin{array}{l}\text { Chapman } \\
\text { and Martin, }{ }^{38} \\
2011\end{array}$ & $\begin{array}{l}20 \text { IBS vs } 33 \text { healthy controls; } \\
\text { females: } 18 \text { in IBS and } 21 \text { in HC; } \\
\text { mean age: } 31 \text { vs } 27\end{array}$ & Modified exogenous cueing task & Hot cognition: attention & $\begin{array}{l}\text { Hospital Anxiety and Depression } \\
\text { Scale, Social Phobia Scale, } \\
\text { Social Interaction Anxiety Scale }\end{array}$ \\
\hline $\begin{array}{l}\text { Tkalcic et } \\
\text { al },{ }^{37} 2014\end{array}$ & $\begin{array}{l}27 \text { IBS and } 28 \text { control; age-and } \\
\text { sex-matched; mean age: } 46 ; \mathrm{M}: \mathrm{F} \\
=1: 5\end{array}$ & $\begin{array}{l}\text { Global/local task, emotional } \\
\text { Stroop test: neutral, symptom- } \\
\text { related and emotionally and } \\
\text { situationally relevant }\end{array}$ & $\begin{array}{l}\text { Hot cognition: attention, } \\
\text { selective attention, cognitive } \\
\text { flexibility and inhibition }\end{array}$ & $\begin{array}{l}\text { State Trait Anxiety Inventory- } \\
\text { Trait scale, Big Five Inventory } \\
\text { (neuroticism), Visceral } \\
\text { Sensitivity Index }\end{array}$ \\
\hline $\begin{array}{l}\text { Fent et al, }{ }^{47} \\
1999\end{array}$ & $\begin{array}{l}21 \text { IBS }(\mathrm{M}: \mathrm{F}=1: 2) \text { vs } 10 \text { healthy } \\
\text { controls }(\mathrm{M}: \mathrm{F}=2: 3)\end{array}$ & $\begin{array}{l}\text { Spatial versus verbal cognitive } \\
\text { tests }\end{array}$ & $\begin{array}{l}\text { For approximation of } \\
\text { hemispheric preference }\end{array}$ & - \\
\hline $\begin{array}{l}\text { Attree et al, }{ }^{42} \\
2003\end{array}$ & $\begin{array}{l}27 \text { IBS }(\mathrm{M}: \mathrm{F}=1: 8) \text { vs } 16 \\
\text { inflammatory bowel disease } \\
(\mathrm{M}: \mathrm{F}=1: 3) \text { vs control }(\mathrm{M}: \mathrm{F}= \\
1: 8)\end{array}$ & $\begin{array}{l}\text { Weschler Abbreviated Scale } \\
\text { of Intelligence, Stroop test, } \\
\text { computer-generated virtual } \\
\text { environment }\end{array}$ & $\begin{array}{l}\text { Verbal and performance IQ, } \\
\text { cognitive flexibility, spatial and } \\
\text { object recognition memory }\end{array}$ & $\begin{array}{l}\text { Center for Epidemiological } \\
\text { Studies Depression scale }\end{array}$ \\
\hline $\begin{array}{l}\text { Aizawa et } \\
\text { al, }{ }^{44} 2012\end{array}$ & $\begin{array}{l}30 \text { IBS vs } 30 \text { control; age-, sex-, } \\
\text { and education-matched; mean } \\
\text { age: } 21 ; \mathrm{M}: \mathrm{F}=1: 1\end{array}$ & $\begin{array}{l}\text { Wisconsin Card Sorting Test } \\
\text { and event-related functional } \\
\text { magnetic resonance imaging, } \\
\text { Wechsler Adult Intelligence Scale } \\
\text { Revised (to exclude subjects } \\
\text { with intellectual functioning } \\
\text { impairment) }\end{array}$ & $\begin{array}{l}\text { Cold cognition: frontal } \\
\text { executive function }\end{array}$ & $\begin{array}{l}\text { Structured Clinical Interview } \\
\text { from the Diagnostic and } \\
\text { Statistical Manual of Mental } \\
\text { Disorders, fourth edition (for } \\
\text { exclusion of subjects with } \\
\text { psychiatric disorders); Profile of } \\
\text { Mood States (for exclusion of } \\
\text { subjects with anxiety/depression) }\end{array}$ \\
\hline $\begin{array}{l}\text { Berrill et al, }{ }^{41} \\
2013\end{array}$ & $\begin{array}{l}40 \text { IBS }(\mathrm{M}: \mathrm{F}=1: 2) \text { vs } 150 \\
\text { inflammatory bowel disease } \\
(\mathrm{M}: \mathrm{F}=1: 2) \text { vs } 41 \text { controls }(\mathrm{M}: \mathrm{F} \\
=2: 3)\end{array}$ & $\begin{array}{l}\text { Two-choice Reaction Time test, } \\
\text { forward digit span task, Paired } \\
\text { Associates Learning, Stroop } \\
\text { test (two-stepped task with and } \\
\text { without interference), timed } \\
\text { verbal and numeric reasoning test, } \\
\text { National Adult Reading Test }\end{array}$ & $\begin{array}{l}\text { Psychomotor speed, working } \\
\text { memory, visuospatial episodic } \\
\text { memory, attention without } \\
\text { interference, cognitive } \\
\text { flexibility with interference, } \\
\text { fluid intelligence, crystallised } \\
\text { intelligence }\end{array}$ & $\begin{array}{l}\text { Hospital Anxiety and Depression } \\
\text { Scale }\end{array}$ \\
\hline $\begin{array}{l}\text { Kennedy et } \\
\mathrm{al}^{40} 2014\end{array}$ & $\begin{array}{l}39 \text { IBS vs } 18 \text { inflammatory } \\
\text { bowel disease vs } 40 \text { healthy } \\
\text { controls; age-and IQ-matched; } \\
\text { mean age: } 28 \text { vs } 28 \text { vs } 32 ; \mathrm{M}: \mathrm{F} \\
=1: 4\end{array}$ & $\begin{array}{l}\text { Cambridge Neuropsychological } \\
\text { Test Automated Battery: Paired } \\
\text { Associates Learning, spatial } \\
\text { working memory, Intra-Extra } \\
\text { Dimensional Set Shift, Stroop test }\end{array}$ & $\begin{array}{l}\text { Cold cognition: visuospatial } \\
\text { episodic memory, working } \\
\text { memory, frontal executive } \\
\text { function, cognitive flexibility }\end{array}$ & $\begin{array}{l}\text { Hospital Anxiety and } \\
\text { Depression Scale, Patient Health } \\
\text { Questionnaire (9-item) }\end{array}$ \\
\hline $\begin{array}{l}\text { Hubbard et } \\
\mathrm{al}^{43} 2015\end{array}$ & $\begin{array}{l}15 \text { IBS vs } 14 \text { healthy controls; all } \\
\text { females; mean age: } 31\end{array}$ & $\begin{array}{l}\text { Attention Network Test and } \\
\text { functional magnetic resonance } \\
\text { imaging }\end{array}$ & Cold cognition: attention & $\begin{array}{l}\text { Hospital Anxiety and Depression } \\
\text { Scale (for exclusion of subjects } \\
\text { with high anxiety/depression), } \\
\text { State Trait Anxiety Inventory }\end{array}$ \\
\hline
\end{tabular}




\section{Outcome}

BS patients had bias for emotionally negative materials; similar to depressed patients IBS patients made significantly more false-positive type errors for emotionally negative materials

\section{Correlation between cognition and bowel symptoms}

IBS patients made significantly more false-positive type errors for emotionally negative materials

\section{Correlation between cognition} and IBS chronicity

\section{$-$}

\section{Correlation between cognition and anxiety/depression}

Word recognition, memory performance not correlated with depressive symptoms

IBS patients showed increased selective recall of gastrointestinal-related words compared with asthma patients and healthy controls

For IBS patients, significant interference of gastrointestinal-symptom-related words was found in masked condition but not in unmasked condition; whereas healthy controls demonstrated the opposite pattern

Compared with organic gastrointestinal patients, IBS patients recognised words related to gastrointestinal symptoms and both positive and negative affects faster, and tended to falsely recall gastrointestinal-symptoms words, suggesting hypervigilance

Post rumination, patients with putative functional gastrointestinal disorders oriented more to social threat words than controls but responded similarly to neutral and pain words

IBS patients were more biased towards pain than neutral words, showing faster engagement with pain words than controls

IBS patients showed attentional bias to situational threat words; trait and visceral anxiety were positively correlated with Stroop facilitation in situational threat words; facilitation of emotional words positively correlated with neuroticism in controls

\section{Biased attention is positively} associated with symptom severity ratings and illness behaviour
Time since IBS
No correlation diagnosis positively correlated with bias to social threats

Distension thresholds were lower in spatial than verbal in IBS patients; the reverse was true in healthy controls

Compared with controls, both IBS and inflammatory bowel disease patients had lower verbal IQ than their own performance IQ

IBS patients performed similarly to controls in Stroop test and virtual environment

IBS subjects had significantly more Nelson perseverative errors and set-maintenance difficulties than controls

Neuroticism was negatively associated with global precedence; trait and visceral anxiety were positively associated with attentional bias elicited by threatening stimuli

$-$

Included as covariate Included as covariate in analysis, in analysis. No significant effect on outcome main outcome no significant effect on main

No correlation with chronicity

Compared with controls, inflammatory bowel disease patients had lower scores on fluid and crystallised intelligence after controlling for age and sex; IBS patients performed similarly to controls in all tests
IBS severity had no effect on cognitive performance by regression analysis
Included as covariate in analysis, cognitive differences between inflammatory bowel disease and control was nullified
IBS patients demonstrated significant impairment in visuospatial memory performance, compared with controls (but not with patients with inflammatory bowel Associates Learning
disease)

More efficient alerting and orienting network in IBS patients
Positive correlation between alerting efficiency and abdominal pain and symptom severity; between executive control efficiency and symptom severity in IBS patients

$\begin{array}{ll}\text { No correlation } & \text { No correlation } \\ \text { between disease } & \\ \text { duration and Paired } & \\ \text { Associates Learning } & \end{array}$

Network efficiency scores not correlated with depression or anxiety ratings 
Given the paucity of studies examining the effect of bowel symptom severity/chronicity on cognitive measures, it is difficult to conclude whether the cognition-chronicity correlation was specific to hot cognitive measures. A positive correlation between attentional bias and both somatic symptoms and chronicity is consistent with a learning model, in which attentional bias to threat and pain increases visceral anxiety, which refers to hypervigilance to bowel symptoms and avoidance of situations where symptoms may occur. ${ }^{50}$ The vicious cycle caused by the reinforcing effect of heightened stress response and bowel symptoms would be consistent with an attention-chronicity correlation. The exact process explaining correlation of bowel symptom severity and chronicity with attention bias to social threat remains to be investigated, but it suggests that the effect of associative learning through the experience of social embarrassment as a result of the disabling nature of bowel symptoms (such as flatulence and diarrhoea) that commonly lead to interruptions in normal social roles and embarrassment. ${ }^{3}$ Future studies should address the correlation between illness chronicity and various cold cognitive performance measures, such as executive function and memory. Given that visuospatial memory impairment in IBS reflects a stress-related HPA-axis response, longitudinal studies should provide salient information as to whether chronic bowel symptoms would result in increased memory impairment as a function of hippocampal changes.

\section{IBS Subtypes}

One potential factor accounting for the heterogeneity of findings may ensue from the subtyping of IBS. The extant studies on cognitive attributes of IBS patients did not specify or separately compared patients according to their constipation or diarrhoea predominance. Compared with IBS-C and healthy subjects, IBS-D patients showed increased proinflammatory cytokines from peripheral blood mononuclear cells that sensitise colonic afferents to mechanical stimuli and are associated with pain. ${ }^{51}$ Given the evidence suggesting association between overexpression of proinflammatory cytokines and hippocampal-mediated memory functions, differences in proinflammatory profiles in IBS-C and IBS-D patients may lead to different cognitive dysfunctions in these subtypes. ${ }^{52}$ Imaging studies suggested that IBS-C patients had increased amygdala and hippocampus activation to rectal distension compared with IBS-D patients who showed more prominent prefrontal hypoactivation. ${ }^{53}$ Further studies comparing neurocognitive profiles in IBS-C and IBS-D patients should yield greater insights into the functional neural networks underlying these IBS subtypes.

\section{Anxiety and Depressive Comorbidity}

Depression and anxiety, on both symptomatic and disorder levels, are common in IBS patients. ${ }^{54}$ Impairment in cognitive functions in patients with depression, including executive function, episodic memory, semantic memory, visuospatial memory, and information processing speed, has been reported. ${ }^{55-57}$ Attentional bias for external negative cues is fairly consistent in patients with generalised anxiety disorder. ${ }^{58}$ Impairment in episodic memory and executive dysfunction has been reported in patients with panic disorder and obsessive-compulsive disorder. ${ }^{59}$ In IBS studies, self-report anxiety and depressive symptom ratings such as Hospital Anxiety and Depression Scale were commonly used. A correlation with cognitive measures has been suggested, though not consistent, across studies, nor consistently measured in the studies reviewed. For example, trait anxiety and visceral anxiety were associated with Stroop facilitation towards social threat words, and higher level of neuroticism was correlated with weaker global precedence in global/local tasks. ${ }^{37}$ However, it was uncertain to what extent the cognitive alterations could be accounted for by depression and anxiety on the disorder level. A more systematic and specific examination of the effect of psychiatric comorbidity on cognitive alterations in IBS patients is needed.

\section{Implications}

IBS patients show deficits in both hot and cold cognitions. Specifically, they have selective attentional bias towards negative emotion and gastrointestinal symptom-related stimuli, indicating upregulation of the arousal system. There is evidence to support a correlation of attentional bias with bowel symptoms severity and chronicity, suggesting a 'state' nature of the hot cognition and possibly disease burden. For cold cognition, the current literature supports executive dysfunctions, hippocampal-mediated visuospatial memory impairment, and attentional deficit in IBS patients. In the cognitive neurobiological model of IBS, cold cognition deficits reflect cognitive impact of various key pathophysiological processes in IBS, including stress response, immune activation, chronic pain, altered microbiota composition, and aberrations in neural networks. In five studies analysing associations between cognitive functions and chronicity and/or bowel symptom severity, all but one reported no association between cognitive function and current bowel symptoms severity and chronicity, suggesting a possible 'trait' nature of cold cognition impairment in IBS..$^{40-44}$ However, none of the eight studies examining the impact of state anxiety and depression on cognitive dysfunction in IBS reported significant association, suggesting that the cognitive impairment in IBS patients was not attributable to anxiety and depressive symptoms. ${ }^{33,35,37,39-43}$

\section{Limitations}

There are some limitations to the current review. The number of studies was small. The sample composition and methodology of studies were diverse, making comparisons difficult. Few studies examined the correlation of cognitive dysfunctions with bowel symptoms severity and chronicity. No study with longitudinal design was available to inform 
state-trait nature and directions of causality of cognitive impairment in IBS. The cognitive impact of comorbid anxiety and depression on disorder levels has not been adequately addressed. The issue of heterogeneity in the bowel symptoms of IBS was not addressed, particularly the neurocognitive differences across various IBS subtypes. Future studies with a priori sample size planning and longitudinal design may improve the understanding of neurocognitive aetiologies, disease mechanism of IBS, and the role these central aberrations play in the brain-immunegut dysfunction. Novel treatment strategies targeting at improving the neurocognitive functioning of IBS patients may be developed.

Our review of the literature supports dysfunctions in frontal executive function, attention, and visuospatial memory in IBS patients and therefore the cognitive neurobiological model. We reviewed the nature of cognitive dysfunctions, subtype differences, and the impact of anxiety/ depression comorbidities; all help inform future research directions. However, the small number of studies reviewed and the various methodology and cognitive domains tested preclude quantitative analyses on the magnitude of differences or associations.

\section{Conclusion}

The current literature on cognitive dysfunction in IBS lacks specific examination of the effects of bowel symptom severity and chronicity, the role of anxiety and depressive comorbidity on a disorder level, and the differences in constipation and diarrhoea predominant IBS subtypes. Longitudinal studies may help delineate the state/trait characteristics of the cognitive dysfunctions. Further studies to examine the effect of systemic pathophysiological changes (such as those in the microbiome, immune, and HPA systems) may yield insights into the multi-system patho-aetiological interactions in IBS, and help identify novel therapeutic targets.

\section{References}

1. Gwee KA. Irritable bowel syndrome in developing countries: a disorder of civilization or colonization? Neurogastroenterol Motil 2005;17:317-24. Crossref

2. Lee S, Wu J, Ma YL, Tsang A, Guo WJ, Sung J. Irritable bowel syndrome is strongly associated with generalized anxiety disorder: a community study. Aliment Pharmacol Ther 2009;30:643-51. Crossref

3. Spiegel BM. The burden of IBS: looking at metrics. Curr Gastroenterol Rep 2009;11:265-9. Crossref

4. Mayer EA, Labus JS, Tillisch K, Cole SW, Baldi P. Towards a systems view of IBS. Nat Rev Gastroenterol Hepatol 2015;12:592-605. Crossref

5. Carabotti M, Scirocco A, Maselli MA, Severi C. The gut-brain axis: interactions between enteric microbiota, central and enteric nervous systems. Ann Gastroenterol 2015;28:203-9.

6. Farmer AD, Aziz Q. Gut pain \& visceral hypersensitivity. Br J Pain 2013;7:39-47. Crossref

7. Jarrett ME, Kohen R, Cain KC, Burr RL, Poppe A, Navaja GP, et al. Relationship of SERT polymorphisms to depressive and anxiety symptoms in irritable bowel syndrome. Biol Res Nurs 2007;9:1619. Crossref

8. Kilpatrick LA, Gupta A, Heendeniya N, Labus JS, Mayer EA.
Corticotropin releasing hormone receptor 1 and progesterone receptor polymorphisms interact with early life trauma in healthy controls and patients with irritable bowel syndrome. Gastroenterology 2013;144:S121.666. Crossref

9. Saito YA, Larson JJ, Atkinson EJ, Ryu E, Elder AEA, Lee RM, et al. A candidate gene association study of functional "psychiatric" polymorphisms in irritable bowel syndrome. Gastroenterology 2010;138:S-90. Crossref

10. Grover M, Camilleri M, Smith K, Linden DR, Farrugia G. Postinfectious irritable bowel syndrome: mechanisms related to pathogens. Neurogastroenterol Motil 2014;26:156-67. Crossref

11. Spiller R, Garsed K. Postinfectious irritable bowel syndrome. Gastroenterology 2009;136:1979-88. Crossref

12. Kennedy PJ, Clarke G, Quigley EM, Groeger JA, Dinan TG, Cryan JF. Gut memories: towards a cognitive neurobiology of irritable bowel syndrome. Neurosci Biobehav Rev 2012;36:310-40. Crossref

13. Tillisch K, Mayer EA, Labus JS. Quantitative meta-analysis identifies brain regions activated during rectal distension in irritable bowel syndrome. Gastroenterology 2011;140:91-100. Crossref

14. Blankstein U, Chen J, Diamant NE, Davis KD. Altered brain structure in irritable bowel syndrome: potential contributions of pre-existing and disease-driven factors. Gastroenterology 2010;138:1783-9. Crossref

15. Wingenfeld K, Rullkoetter N, Mensebach C, Beblo T, Mertens M, Kreisel S, et al. Neural correlates of the individual emotional Stroop in borderline personality disorder. Psychoneuroendocrinology 2009;34:571-86. Crossref

16. Aisa B, Tordera R, Lasheras B, Del Río J, Ramírez MJ. Cognitive impairment associated to HPA axis hyperactivity after maternal separation in rats. Psychoneuroendocrinology 2007;32:256-66. Crossref

17. Aisa B, Tordera R, Lasheras B, Del Rio J, Ramirez MJ. Effects of maternal separation on hypothalamic-pituitary-adrenal responses, cognition and vulnerability to stress in adult female rats. Neuroscience 2008;154:1218-26. Crossref

18. Frankola KA, Flora AL, Torres AK, Grissom EM, Overstreet S, Dohanich GP. Effects of early rearing conditions on cognitive performance in prepubescent male and female rats. Neurobiol Learn Mem 2010;94:91-9. Crossref

19. Monroy E, Hernández-Torres E, Flores G. Maternal separation disrupts dendritic morphology of neurons in prefrontal cortex, hippocampus, and nucleus accumbens in male rat offspring. J Chem Neuroanat 2010;40:93-101. Crossref

20. Stevenson CW, Spicer CH, Mason R, Marsden CA. Early life programming of fear conditioning and extinction in adult male rats. Behav Brain Res 2009;205:505-10. Crossref

21. Mehta MA, Owen AM, Sahakian BJ, Mavaddat N, Pickard JD, Robbins TW. Methylphenidate enhances working memory by modulating discrete frontal and parietal lobe regions in the human brain. J Neurosci 2000;20:RC65. Crossref

22. Ramos BP, Stark D, Verduzco L, van Dyck CH, Arnsten AF. Alpha2Aadrenoceptor stimulation improves prefrontal cortical regulation of behavior through inhibition of cAMP signaling in aging animals. Learn Mem 2006;13:770-6. Crossref

23. Ramos BP, Arnsten AF. Adrenergic pharmacology and cognition: focus on the prefrontal cortex. Pharmacol Ther 2007;113:523-36. Crossref

24. Birnbaum S, Gobeske KT, Auerbach J, Taylor JR, Arnsten AF. A role for norepinephrine in stress-induced cognitive deficits: alpha1-adrenoceptor mediation in the prefrontal cortex. Biol Psychiatry 1999;46:1266-74. Crossref

25. Codling C, O'Mahony L, Shanahan F, Quigley EM, Marchesi JR. A molecular analysis of fecal and mucosal bacterial communities in irritable bowel syndrome. Dig Dis Sci 2010;55:392-7. Crossref

26. Guglielmetti S, Mora D, Gschwender M, Popp K. Randomised clinical trial: Bifidobacterium bifidum MIMBb75 significantly alleviates irritable bowel syndrome and improves quality of life: a double-blind, placebo-controlled study. Aliment Pharmacol Ther 2011;33:112332. Crossref

27. Gareau MG, Wine E, Rodrigues DM, Cho JH, Whary MT, Philpott DJ, et al. Bacterial infection causes stress-induced memory dysfunction in 
mice. Gut 2011;60:307-17. Crossref

28. Fernandez-Real JM, Serino M, Blasco G, Puig J, Daunis-i-Estadella J, Ricart W, et al. Gut microbiota interacts with brain microstructure and function. J Clin Endocrinol Metab 2015;100:4505-13. Crossref

29. Bantick SJ, Wise RG, Ploghaus A, Clare S, Smith SM, Tracey I. Imaging how attention modulates pain in humans using functional MRI. Brain 2002;125:310-9. Crossref

30. Eccleston C, Crombez G. Pain demands attention: a cognitive-affective model of the interruptive function of pain. Psychol Bull 1999;125:35666. Crossref

31. Moriarty O, McGuire BE, Finn DP. The effect of pain on cognitive function: a review of clinical and preclinical research. Prog Neurobiol 2011;93:385-404. Crossref

32. Metcalfe J, Mischel W. A hot/cool-system analysis of delay of gratification: dynamics of willpower. Psychol Rev 1999;106:3-19. Crossref

33. Gomborone JE, Dewsnap PA, Libby GW, Farthing MJ. Selective affective biasing in recognition memory in irritable bowel syndrome. Gut 1993;34:1230-3. Crossref

34. Gibbs-Gallagher N, Palsson OS, Levy RL, Meyer K, Drossman DA, Whitehead WE. Selective recall of gastrointestinal-sensation words: evidence for a cognitive-behavioral contribution to irritable bowel syndrome. Am J Gastroenterol 2001;96:1133-8. Crossref

35. Posserud I, Svedlund J, Wallin J, Simrén M. Hypervigilance in irritable bowel syndrome compared with organic gastrointestinal disease. J Psychosom Res 2009;66:399-405. Crossref

36. Afzal M, Potokar JP, Probert CS, Munafò MR. Selective processing of gastrointestinal symptom-related stimuli in irritable bowel syndrome. Psychosom Med 2006;68:758-61. Crossref

37. Tkalcic M, Domijan D, Pletikosic S, Setic M, Hauser G. Attentional biases in irritable bowel syndrome patients. Clin Res Hepatol Gastroenterol 2014;38:621-8. Crossref

38. Chapman S, Martin M. Attention to pain words in irritable bowel syndrome: increased orienting and speeded engagement. Br J Health Psychol 2011;16:47-60. Crossref

39. Martin M, Chapman SC. Cognitive processing in putative functional gastrointestinal disorder: rumination yields orientation to social threat not pain. Eur J Pain 2010;14:207-13. Crossref

40. Kennedy PJ, Clarke G, O`Neill A, Groeger JA, Quigley EM, Shanahan $\mathrm{F}$, et al. Cognitive performance in irritable bowel syndrome: evidence of a stress-related impairment in visuospatial memory. Psychol Med 2014;44:1553-66. Crossref

41. Berrill JW, Gallacher J, Hood K, Green JT, Matthews SB, Campbell AK, et al. An observational study of cognitive function in patients with irritable bowel syndrome and inflammatory bowel disease. Neurogastroenterol Motil 2013;25:918-e704. Crossref

42. Attree EA, Dancey CP, Keeling D, Wilson C. Cognitive function in people with chronic illness: inflammatory bowel disease and irritable bowel syndrome. Appl Neuropsychol 2003;10:96-104. Crossref

43. Hubbard CS, Hong J, Jiang Z, Ebrat B, Suyenobu B, Smith S, et al. Increased attentional network functioning related to symptom severity measures in females with irritable bowel syndrome. Neurogastroenterol Motil 2015;27:1282-94. Crossref

44. Aizawa E, Sato Y, Kochiyama T, Saito N, Izumiyama M, Morishita $\mathrm{J}$, et al. Altered cognitive function of prefrontal cortex during error feedback in patients with irritable bowel syndrome, based on FMRI and dynamic causal modeling. Gastroenterology 2012;143:118898. Crossref

45. Hill F, Echemendia RJ. Neuropsychological functioning in adult insulin-dependent diabetes mellitus patients. Arch Clin Neuropsychol 1995; 10:340-1. Crossref

46. Siegel DJ, Minshew NJ, Goldstein G. Wechsler IQ profiles in diagnosis of high-functioning autism. J Autism Dev Disord 1996;26:389406. Crossref

47. Fent J, Balázs L, Buzás G, Erasmus LP, Hölzl R, Kovács Á, et al. Colonic sensitivity in irritable bowel syndrome and normal subjects according to their hemispheric preference and cognitive style. Integr Physiol Behav Sci 1999;34:54-62. Crossref

48. Mineka S, Zinbarg R. A contemporary learning theory perspective on the etiology of anxiety disorders: it's not what you thought it was. Am Psychol 2006;61:10-26. Crossref

49. Shuster J, Toplak ME. Executive and motivational inhibition: associations with self-report measures related to inhibition. Conscious Cogn 2009; 18:471-80. Crossref

50. Drossman DA. Gastrointestinal illness and the biopsychosocial model. J Clin Gastroenterol 1996;22:252-4. Crossref

51. Hughes PA, Harrington AM, Castro J, Liebregts T, Adam B, Grasby DJ, et al. Sensory neuro-immune interactions differ between irritable bowel syndrome subtypes. Gut 2013;62:1456-65. Crossref

52. Marsland AL, Petersen KL, Sathanoori R, Muldoon MF, Neumann $\mathrm{SA}$, Ryan $\mathrm{C}$, et al. Interleukin-6 covaries inversely with cognitive performance among middle-aged community volunteers. Psychosom Med 2006;68:895-903. Crossref

53. Wilder-Smith CH, Schindler D, Lovblad K, Redmond SM, Nirkko A. Brain functional magnetic resonance imaging of rectal pain and activation of endogenous inhibitory mechanisms in irritable bowel syndrome patient subgroups and healthy controls. Gut 2004;53:1595601. Crossref

54. Fond G, Loundou A, Hamdani N, Boukouaci W, Dargel A, Oliveira $\mathrm{J}$, et al. Anxiety and depression comorbidities in irritable bowel syndrome (IBS): a systematic review and meta-analysis. Eur Arch Psychiatry Clin Neurosci 2014;264:651-60. Crossref

55. Northoff G, Wiebking C, Feinberg T, Panksepp J. The 'resting-state hypothesis' of major depressive disorder: a translational subcorticalcortical framework for a system disorder. Neurosci Biobehav Rev 2011;35:1929-45. Crossref

56. McDermott LM, Ebmeier KP. A meta-analysis of depression severity and cognitive function. J Affect Disord 2009;119:1-8. Crossref

57. Liotti M, Mayberg HS. The role of functional neuroimaging in the neuropsychology of depression. J Clin Exp Neuropsychol 2001;23:121-36. Crossref

58. Mogg K, Bradley BP. Attentional bias in generalized anxiety disorder versus depressive disorder. Cognit Ther Res 2005;29:29-45. Crossref

59. Airaksinen E, Larsson M, Forsell Y. Neuropsychological functions in anxiety disorders in population-based samples: evidence of episodic memory dysfunction. J Psychiatr Res 2005;39:207-14. Crossref

60. Drossman DA. Functional gastrointestinal disorders: history, pathophysiology, clinical features and Rome IV. Gastroenterology 2016:S0016-5085(16)00223-7. Crossref 